\title{
Innovative Algorithm for Dosing Prandial Insulin in Patients with Diabetes Undergoing Hemodialysis
}

Eunice Eunyoung Yang, BSN, RN, CNN, CDE Uvannie Palomares Enriquez, MPA, BSN, RN, NEA-B Jane Jeffrie Seley, DNP, MSN, MPH, GNP, CDE, BC-ADM, CDTC, FADDE, FAAN NewYork-Presbyterian/Weill Cornell Medical Center

\section{Problem Identification}

\section{Background}

Patients with diabetes undergoing hemodialysis (HD) have unpredictable oral intake due to uremic symptoms and hemodynamic changes. Previously HD nurses administered prandial insulin doses with no consideration for the amount of carbohydrate $(\mathrm{CHO})$ consumed. Hypoglycemia was common, especially after prandial insulin dosing. Currently, there is no prandial insulin dosing guideline that considers both current blood glucose (BG) and the amount of $\mathrm{CHO}$ consumed for patients with diabetes undergoing $\mathrm{HD}$.

\section{Clinical Question}

Population - Inpatients with diabetes undergoing HD in an acute HD unit receiving a meal tray

Intervention - Administration of prescribed prandial insulin with consideration for current $\mathrm{BG}$ and amount of $\mathrm{CHO}$ consumed $(\geq 30 \mathrm{~g} \mathrm{CHO})$

Comparison - Administer prescribed prandial insulin based on current BG only

Outcome - Target range of of BG (140-180 mg/dL or $7.8-$ $10.0 \mathrm{mmol} / \mathrm{L})$

\section{Evidence Review}

Insulin requirements decrease as renal function declines. ${ }^{1,3}$ The kidney clears and degrades up to $25 \%$ of endogenous insulin. Decreased insulin catabolism overrides insulin resistance. Impaired degradation of insulin contributes to insulin's prolonged half-life. Insulin requirements are often reduced by $50 \%$ in end stage renal disease (ESRD).

\section{Dialysates affect blood glucose. ${ }^{1}$}

Most dialysate solutions contain $100 \mathrm{mg} / \mathrm{dL}$ or $5.6 \mathrm{mmol} / \mathrm{L}$ of glucose. Glucose diffuses easily between blood and dialysate solutions. Patients with hyperglycemia may have BG levels lowered by HD.

Less stringent A1C goal for ESRD/HD patients

- ADA (2019) standards of care: A1C < 8\% (BG $183 \mathrm{mg} / \mathrm{dL}$ or $10.2 \mathrm{mmol} / \mathrm{L}$ ) for patients with a history of advanced microvascular complications ${ }^{2}$

- KDOQI (2012) diabetes guidelines: A1C>7\% (BG $154 \mathrm{mg} / \mathrm{dL}$ or $8.6 \mathrm{mmol} / \mathrm{L})$ for ESRD patients treated with insulin ${ }^{5}$

- A study of 23,296 Canadian patients GFR $<60 \mathrm{ml} / \mathrm{min}$ (2011): No significant increase in mortality at A1C 7.5-8.4\% (BG 169$194 \mathrm{mg} / \mathrm{dL}$ or $9.4-10.8 \mathrm{mmol} / \mathrm{L})^{6}$

Hypoglycemia alert value is a $B G \leq 70 \mathrm{mg} / \mathrm{dL}$ or 3.9 $\mathrm{mmol} / \mathrm{L}$ and clinically significant hypoglycemia is $B G<54 \mathrm{mg} / \mathrm{dL}$ or $3 \mathrm{mmol} / \mathrm{L}^{2}{ }^{2}$

- Treatment: $15 \mathrm{~g}-25 \mathrm{~g} \mathrm{CHO}$ until $\mathrm{BG}>80 \mathrm{mg} / \mathrm{dL}$ or $4.4 \mathrm{mmol} / \mathrm{L}^{2}$

- Based on above references, we hypothesized;

1. 15-25 grams $\mathrm{CHO}$ expected to raise $\mathrm{BG} 10-30 \mathrm{mg} / \mathrm{dL}$ or $0.6-1.7 \mathrm{mmol} / \mathrm{L}$.

2. 30 grams $\mathrm{CHO}$ presumably raise $\mathrm{BG}$ by $20-60 \mathrm{mg} / \mathrm{dL}$ or $1.1-3.3 \mathrm{mmol} / \mathrm{L}$.

\section{New Algorithm}

- June 2016 - present

- Algorithm tested for face validity by departments of Nephrology, Endocrinology, Nursing, and Nutrition

- Unanimous agreement - it is safe and may lead to improved outcomes.

- Monitoring HD nurses compliance to algorithm monthly

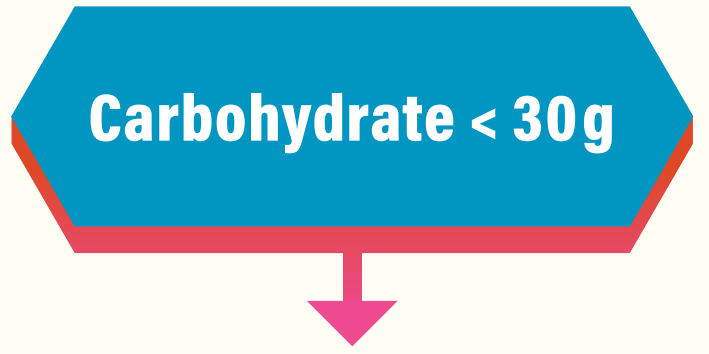

Carbohydrate $\geq 30 \mathrm{~g}$

Do Not Give Insulin

\section{Administer Prandial Insulin}

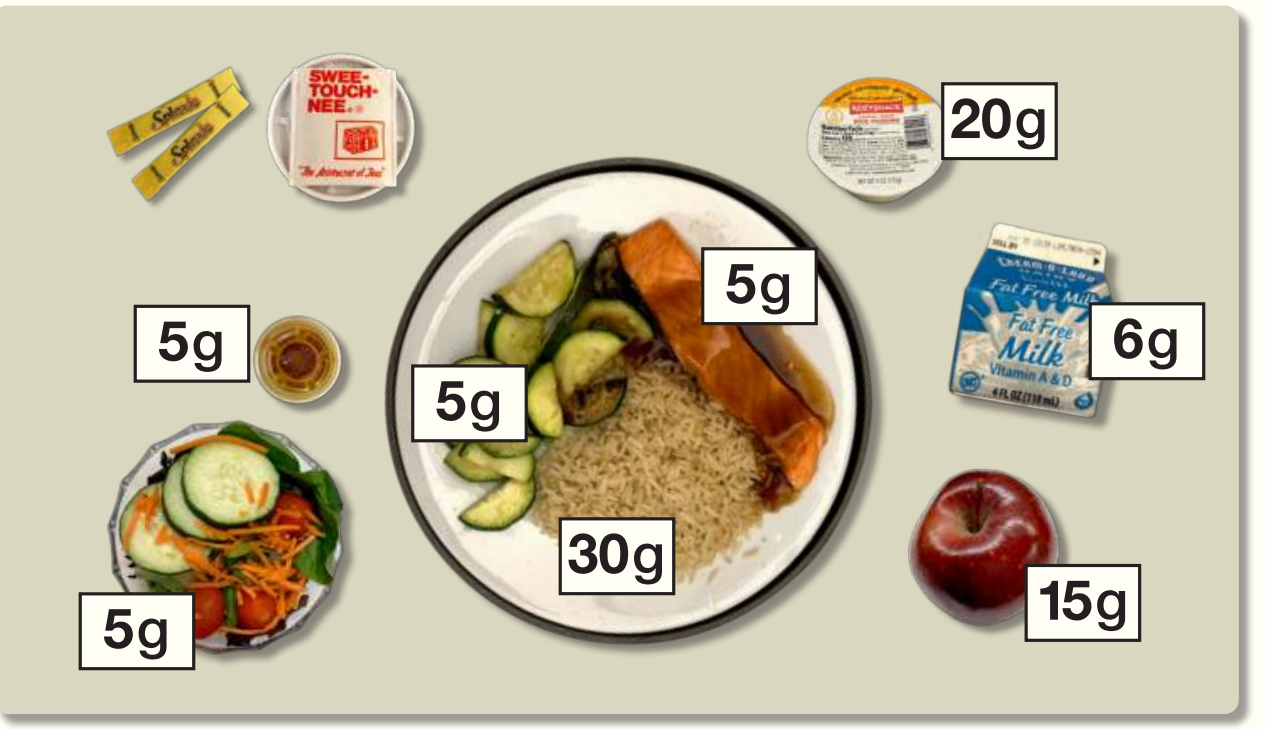

Hemodialysis Diet Sample (Lunch)

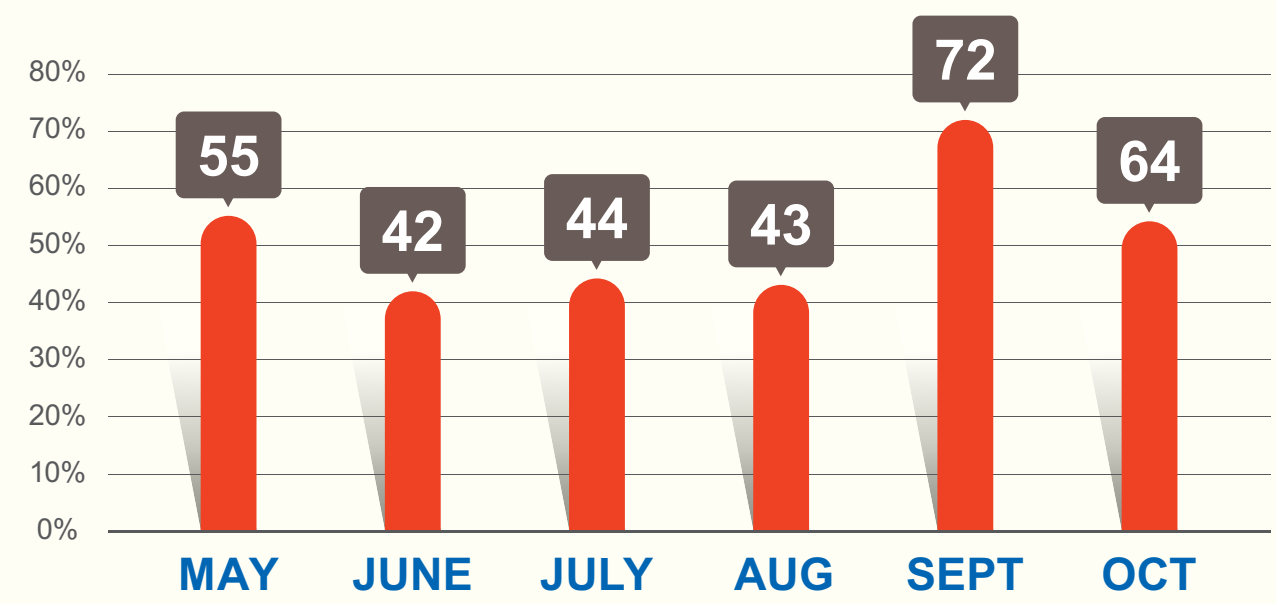

HD Nurses Compliance to New Algorithm (2019)

\section{Research}

- Design - retrospective study in 2017

- Methods - compared pre-post rates of hypoglycemia events using new algorithm

- Results - no significant difference (28.6\% vs $22.5 \%$, chi square test) in rates of hypoglycemia

- Limitation - small sample size $(n=47)$, intervention fidelity issues with algorithm-adherence, and our study design limiting causality

\section{Next Step}

- The algorithm can be safely maintained until efficacy is ascertained by the prospective study in 2020 . 